\title{
Evaluation and improvements regarding the implementation of Project-Based Learning within the Innovative Development program
}

\author{
Lisa Wichgers ${ }^{1}$, Wilan Loots ${ }^{1}$, Tim Cocx $^{2}$, Hani Alers ${ }^{2}$ \\ ${ }^{1}$ Faculty of Social Work and Education, ${ }^{2}$ Faculty of IT \& Design, The Hague University of \\ Applied Sciences, the Netherlands.
}

\begin{abstract}
This research evaluates how Project-Based Learning (PBL) is implemented in the Innovative Development program that is taught at The Hague University of Applied Sciences. This paper offers insights about the way students and instructors experience PBL within this program, and how the implementation can be improved according to previous research in this field. By studying relevant literature, a list of important (organizational and didactical) factors regarding the implementation of PBL is created. Questionnaires investigating these factors are then circulated among the instructors and students of the program. The results of the questionnaires are analyzed against guidelines provided in the literature. Based on this comparison, recommendations for the improvement of the PBL approach within the program are provided.

The analysis shows that the program offers meaningful projects, and the students are properly prepared to collaborate. Nevertheless, the analysis also shows that the program still has room for improvement. The assessment methods are still unrefined, the students experience time-pressure while working on their projects, and the instructors can benefit from additional training to be better prepared for teaching in a PBL environment. Fortunately, the instructors indicate willingness to learn new PBL specific teaching skills.
\end{abstract}

Keywords: PBL; project-based learning; organizational and didactical factors. 


\section{Introduction}

\subsection{Project-Based Learning}

Project-Based Learning (PBL) is a learning method that motivates learners to gain knowledge and skills through working on real-life projects (Krajcik \& Blumenfeld, 2006). In this method there are neither scheduled lectures, nor theoretical exams. Students choose a project that is personally meaningful to them and work on it for an extended period of time (Krajcik \& Blumenfeld, 2006).

Research shows the effect of PBL on the following eight life skills: responsibility, problem solving, self-direction, communication, creativity, time management, collaboration and work-ethic (Helle, Tynjala,\& Olkinuora, 2006). Students who followed a 16-week PBL course for an experiment by Wurdinger and Qureshi (2015) showed improvement on five out of these eight skills. When PBL is successfully executed, students feel involved and motivated. By producing complex and high-quality work, this increases their learning motivation (Sumarni, 2015). Aside from causing a high intrinsic motivation, PBL is also said to cause high levels of student engagement. Whilst students work on their projects, they have to solve problems that come up during the process. This causes students to experience freedom and challenges, resulting in high levels of student engagement (Wurdinger, Haar, Hugg, \& Bezon, 2007).

Even though PBL is widely encouraged, Holubova (2008) points out that there are also some disadvantages to the method. They describe that not all instructors are qualified to teach the way PBL needs to be taught. Another disadvantage is the lack of evidence-based instructional strategies that describe which facets of project-based learning are important for particular kinds of outcomes, so that educators can make informed choices in adapting project-based learning to their particular contexts (Holubova, 2008). Different sources offer discussion points regarding necessary improvements in PBL. Helle et al. (2006) state that there needs to be more theoretically grounded research about PBL. There should be a clearer definition of the goals within the curriculum, and the congruence between stated goals and the activity of the students should be more engaged and clearer (Helle et al., 2006). A great obstacle within PBL is the assessment. There are no clear guidelines about the way assessments should be graded and who should do the assessing. As a whole, the curriculum of PBL is difficult to optimize. The purpose of PBL is still vaguely defined and some organizational and didactical factors remain vague for both instructors and students.

\subsection{The innovative development program}

Innovative Development (ID) is one of the five programs within the ICT bachelor's degree that is taught at The Hague University of Applied Sciences (THUAS). The ID program employs a PBL approach wich offers freedom and flexibility. The students work on a new 
project every semester for 18 weeks. Every student decides what project they want to work on. Students can come up with their own projects or choose from a list of projects offered by externl entities such as companies. The students who choose the same project are placed in a group. Every group is assigned to an instructor who supports them throughout the entire project. To guide their learning, there is a list of competences that require certain knowledge and skills to be achieved. In this so called 'competence tree', the competences are specified and divided into proficiency levels. For every project, the students decide which of these competences fit their project. The students and instructors regularly meet in progress appointments, where the students have to prove that they have gained enough knowledge and skills to achieve a certain proficiency level of the chosen competences.

\subsection{Methodology}

This research evaluates the way PBL is being implemented within ID and recommends ways to improve the implementation. To do so, desk research is performed to identify the organizational and didactical factors important for implementing PBL. Questionnaires based on these factors are sent out to the students and instructors of ID. The results of the questionnaires are compared to recommendations in the literature about how PBL should be implemented. Finally, a list of recommendations for improvements is provided.

\section{Methodology}

\subsection{Didactical and organizational factors}

We start by exploring the literature for ways to measures the organizational and didactical factors that are relevant for a proper implementation of PBL. The result is a list of important factors regarding these concepts, which are repeatedly mentioned in earlier research. This list includes the following factors: meaningful projects, element of choice, group work, guided inquiry, instructor support, assessment, and the competence of instructors.

\subsection{Measuring instruments}

Based on the above mentioned factors, two questionnaires are constructed. One questionnaire aimed at the Students while the other targeted the instructors. Both questionnaires focus on the same factors, but the questions are formulated differently to fit relevant situations for both students and instructors. To explore how the program is being taught, the questionnaires consist of open questions. This helps to gain interesting insights in the process. For example, about instructor support, to not only find out whether the students experience instructor support, but also in what ways they do so. 


\section{Results}

To describe the results, the data gathered from the questionnaires is analyzed by applying the grounded theory approach. By doing this, the answers are reduced to labels that can be categorized. These labels show how PBL is being implemented in ID and what opinion instructors and students have on this implementation. This chapter describes how the important organizational and didactical factors (discussed in Section 2.1) are implemented in ID based on the answered questionnaires.

\subsection{Meaningful projects and an element of choice}

\subsubsection{The current implementation in ID}

The first step in a PBL cycle is for the students to decide what project they will work on. When the instructors collect projects for the students to choose from, they look for several qualities. First, it has to be a real project that comes from a real owner. The collaboration with the owner is important throughout the entire project, so the project owner has to be willing to actively collaborate for a period of 18 weeks. Second, the project has to be challenging and flexible.

\subsubsection{Student experience}

The students expressed satisfaction with the projects they are offered, saying that they are meaningful and interesting for them. All students who answered the questionnaire agreed that they are free to choose what project they want to work on and can even propose their own project ideas.

\subsection{Group work}

\subsubsection{The current implementation in $I D$}

The students are placed into project groups, based on the project they have chosen. In the first year of ID, the students get training for the collaboration skills that they will need for the remainder of the program. Students learn how to make team agreements, give proper feedback, and receive feedback. Every project cycle of 18 weeks is divided into so called 'sprints' of three weeks. At the beginning of a sprint, the groups make a list of the goals they have for that period. The project groups keep track of their tasks and progress using a Scrum board, on which they organize what they have to do, what they are currently doing and finally what is done. This method doubles as a progress log, since the board shows exactly what tasks have been done within a sprint. At the end of a sprint, the project groups evaluate the progress, reflect on how the sprint went, and prepare for the next sprint. 


\subsubsection{Student experience}

Students often have to change their approach after a sprint, the main reason for this being a lack of time. Most of the students said they experience time-pressure when working on a project. Some students mentioned that using a Scrum board supports them in helping each other, because they can easily see what tasks need to be worked on.

\subsection{Guided inquiry and instructor support}

\subsubsection{The current implementation in ID}

Every school day is commenced with a 'daily start', where announcements are made and students get the opportunity to ask questions. Every instructor is assigned to two to four project groups, as well as to approximately 10 students for individual support. project groups have regular appointments with their assigned instructor. In these meetings, the instructors coach the groups, look at their planning and keep track of the competences they are working on at that moment. In an individual meeting, the students and instructors focus mainly on the students' role in their project groups and on their study progress.

\subsubsection{Student experience}

The students are satisfied with the contact with their instructors, saying they can easily reach out to an instructor to arrange an extra meeting or a lecture on a certain topic. Some students have pointed out that they would appreciate more personal guidance, while others are content with the way that this is currently organized.

\subsection{Assessment}

\subsubsection{The current implementation in ID}

The students receive a grade based on their progress during a project. At the end of a project cycle, the instructors also decide whether the students has achieved the required proficiency level of the competence they have worked on.

\subsubsection{Student and instructor experience}

Both the instructors and students pointed out that the assessing and grading remains unclear within ID. The instructors said that it is clear to the groups what the focus points of the assessment will be. The students, however, said they are often uncertain of the way the assessment will be performed and what exactly will be assessed. 


\subsection{Instructors' competence}

\subsubsection{The current implementation in ID}

To get prepared for teaching in a PBL environment, an instructor noted that he performed observations in a program that was already implementing PBL and read into the literature. All of the instructors who answered the questionnaire are willing to learn more about PBL, to improve their teaching approach in the program.

\subsubsection{Student experience}

There were no complaints from the students about the competence of the instructors.

\section{Analyzing results based on the PBL factors}

The previous section contains the results of the questionnaires, showing the way PBL is currently implemented in ID. When comparing the way the important factors are being described in previous research, and the way they are being implemented in ID, there are some noticeable differences. This section analyses the results described in Section 3, based on the recommendations in the literature. This analysis, along with the student and instructor suggestions, give insights on how the implementation of PBL can be improved within ID.

\subsection{Meaningful projects and an element of choice}

It seems like the instructors put effort in finding meaningful projects and succeed while doing this. The students who answered the questionnaire agree that the projects are personally meaningful to them. They also get to decide exactly what project they would like to work on, which proves there is a certain element of choice within the program. According to Lam, Wing-yi Cheng and Ma (2009), a meaningful and challenging project highly increases students' motivation.

\subsection{Group work}

Sumarni (2015) describes the necessity of teaching students how to interact in a group and manage conflict within the group, when they do not have experience with working in groups. The students' satisfaction with the collaboration within their groups, could be caused by the attention that is paid to collaboration skills in the first semester of the program.

The project groups are formed based on the project the students decide to work on. To positively influence the collaboration within the groups, instructors could also take the individual students' skills into consideration. According to Sumarni (2015), instructors should combine students with opposite competences to make groups that support and help each other. 
All students who answered the questionnaire say that they experience some level of timepressure. By including time-management in the list of skills the students work on in the first semester, the time-pressure that the students experience while working on a project may possibly be lowered.

\subsection{Guided inquiry, instructor support and assessment}

The students do not have a clear vision of the way their project will be assessed, when they start working on a new project. This could be improved by the students and instructors clearly writing down agreements regarding the assessment, so both know what to expect. Helle et al. (2006) mention that given PBL's independent character (student's initiative, self-regulation, self-reflection), self-assessment should be a part of assessment. Including this in the final assessment, can improve the overall assessment process.

Students also point out that some of the lectures they requested, on broad research topics, can be of interest for multiple groups. They suggest that there could be a small, optional, course scheduled about these topics.

Finally, several students mentioned they would appreciate guidance on a more personal level. It is highly recommended to focus on the teacher-student relationship as much as possible, to help the students stay motivated (Sumarni, W., 2015). There are also students who are not at all interested in this type of personal guidance. By offering optional student- instructor sessions, the instructors could possibly respond to the individual students' needs.

\subsection{Instructors' competence}

According to Sumarni (2015), the transition from a traditional classroom to a PBL environment can be difficult for both experienced and novice instructors. To increase the instructors' skills, Sumarni recommends developing a learning program for instructors that is based on the PBL approach. This could be valuable to both the current instructors, who have said to be willing to learn more about PBL, as well as to future instructors joining ID.

\section{Conclusions and recommendations}

\subsection{Conclusions}

This research explored how the implementation of PBL can be improved within THUAS' ID program. To answer this question, the ID implementation was analysed against the most important PBL factors in the literature. The analysis of the results reveals some positive points within the current implementation of PBL. The most notable positive points are:

- Choosing meaningful projects;

- students' collaboration skills; 
- $\quad$ instructors' flexibility and will to learn more about PBL.

In contrast, the analysis also shows negatives in need of improvements. These are:

- More attention to time-management skills;

- clarity regarding assessment;

- $\quad$ possibilities for more personal guidance;

- improving instructors' skills regarding the PBL approach.

\subsection{Recommendations}

Further research should focus on applying structure within the ID program. Besides that, the assessment method needs improvement. This issue, however, is a recurring factor in most of the literature available on PBL. There is no standard assessment method that can be applied to every project.

\section{References}

Helle, L., Tynjälä, P., \& Olkinuora, E. (2006). Project-based learning in post-secondary education-theory, practice and rubber sling shots. Higher education, 51(2), 287-314. DOI: $10.1007 / \mathrm{s} 10734-004-6386-5$

Holubova, R. (2008). Effective Teaching Methods--Project-based Learning in Physics. Online Submission, 5(12), 27-36.

Krajcik, J.S., \& Blumenfeld, P.C. (2006). Chapter 19: Project-based learning. In Sawyer, R. K. (2006). The new science of learning. The Cambridge handbook of the learning sciences, 1, 18. (pp. 317-34) Cambridge, England: Cambridge University Press.

Lam, S. F., Cheng, R. W. Y., \& Ma, W. Y. (2009). Teacher and student intrinsic motivation in project-based learning. Instructional Science, 37(6), 565. DOI: 10.1007/s11251-0089070-9.

Larmer, J., \& Mergendoller, J. R. (2010). Seven essentials for project-based learning. Educational leadership, 68(1), 34-37.

Sumarni, W. (2015). The strengths and weaknesses of the implementation of project based learning: A review. International Journal of Science and Research, 4(3), 478-484.

Wurdinger, S., Haar, J., Hugg, R., \& Bezon, J. (2007). A qualitative study using projectbased learning in a mainstream middle school. Improving schools, 10(2), 150-161. DOI: $10.1177 / 1365480207078048$

Wurdinger, S., \& Qureshi, M. (2015). Enhancing college students' life skills through project based learning. Innovative Higher Education, 40(3), 279-286. DOI 10.1007/s10755-0149314-3. 